\title{
Synthesis and Antioxidant Activities of Novel 5-Chlorocurcumin, Complemented by Semiempirical Calculations
}

\author{
Ahmed A. Al-Amiery, ${ }^{1,2}$ Abdul Amir H. Kadhum, ${ }^{1}$ \\ Hasan R. Obayes, ${ }^{2}$ and Abu Bakar Mohamad ${ }^{1}$ \\ ${ }^{1}$ Department of Chemical \& Process Engineering, Universiti of Kebangsaan Malaysia (UKM), 43000 Bangi, Selangor, Malaysia \\ ${ }^{2}$ Applied Chemistry Division, Applied Science Department, University of Technology (UOT), Baghdad 10001, Iraq
}

Correspondence should be addressed to Ahmed A. Al-Amiery; dr.ahmed1975@gmail.com

Received 31 July 2013; Revised 19 August 2013; Accepted 20 August 2013

Academic Editor: Enrico Rizzarelli

Copyright ( 2013 Ahmed A. Al-Amiery et al. This is an open access article distributed under the Creative Commons Attribution License, which permits unrestricted use, distribution, and reproduction in any medium, provided the original work is properly cited.

\begin{abstract}
The novel curcumin derivative (1E,4Z,6E)-5-chloro-1,7-bis(4-hydroxy-3-methoxyphenyl)hepta-1,4,6-trien-3-one (5-chlorocurcumin) was prepared from natural curcumin. The newly synthesised compound was characterised by spectral studies (IR, $1 \mathrm{H}$ $\mathrm{NMR}$, and 13C NMR). The free radical scavenging activity of 5-chlorocurcumin has been determined by measuring interaction with the stable free radical DPPH, and 5-chlorocurcumin has shown encouraging antioxidant activities. Theory calculations of the synthesised 5-chlorocurcumin were performed using molecular structures with optimised geometries. Molecular orbital calculations provided a detailed description of the orbitals, including spatial characteristics, nodal patterns, and the contributions of individual atoms.
\end{abstract}

\section{Introduction}

Curcumin (1) [diferuloylmethane, 1,7-bis(4-hydroxy-3-methoxyphenyl)-1,6-hepta-diene-3,5-dione] is a well-known acyclic diarylheptanoid identified as the major constituent of turmeric powder extracted from the rhizome of the plant Curcuma longa $[1,2]$. Curcumin (1) has potent antioxidant activity [3-5] and has received attention as a promising nutraceutical or as a component of designer foods for its cancer preventive ability. With a unique conjugated structure including two methoxylated phenols and an enol $\beta$ diketone, curcumin shows a typical radical-trapping ability as a chain-breaking antioxidant. The antioxidant mechanism of curcumin and curcumin-related phenols has attracted significant attention [6-8], but it is still not well understood. In addition, curcumin blocks growth factor signaling via inhibition of tyrosine kinase activity or depletion of ErbB-2 [9]. More recently, it has been shown that curcumin causes cleavage of h-catenin, resulting in apoptosis in a colon cancer-derived cell line [10]. Antioxidant compounds play an important role as a health protecting factor.
Scientific evidence suggests that antioxidants reduce the risk for chronic diseases including cancer and heart disease. Primary sources of naturally occurring antioxidants are whole grains, fruits, and vegetables. Plant sourced food antioxidants like vitamin $\mathrm{C}$, vitamin $\mathrm{E}$, carotenes, phenolic acids, phytate, and phytoestrogens have been recognized as having the potential to reduce disease risk. Most of the antioxidant compounds in a typical diet are derived from plant sources and belong to various classes of compounds with a wide variety of physical and chemical properties. Some compounds, such as gallates, have strong antioxidant activity, while others, such as the monophenols, are weak antioxidants [11]. For instance, in the DPPH (2,2-diphenyl-1-picrylhydrazyl) analysis the antioxidant properties of compounds change as follows: gallic acid $>$ caffeic acid $\sim$ ascorbic acid $\sim$ Trolox $>$ sinapinic acid $>$ isoeugenol [12]. ABTS (2,20-azinobis(3ethylbenzothiazoline-6-sulfonic acid) assay has shown that the sinapinic acid is a weaker antioxidant than the gallic acid but stronger than the rest of the tested compounds [12]. crocin bleaching assay (CBA) test has shown that the sinapinic acid is the strongest antioxidant of all investigated 
<smiles>COc1cc(/C=C/C(=O)/C=C(Cl)/C=C/c2ccc(O)c(OC)c2)ccc1O</smiles>

Figure 1: Structure of 5-chlorocurcumin.

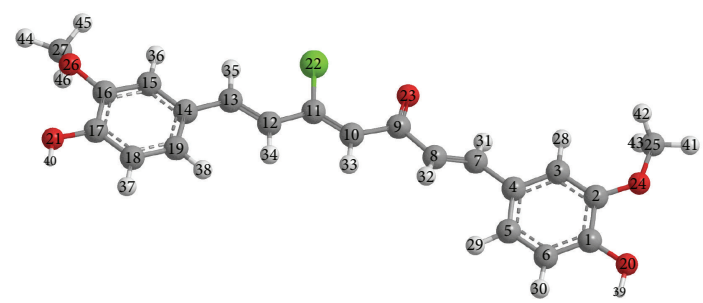

Figure 2: Optimised 3D geometrical structure for 5-chlorocurcumin.

compounds [12]. In Oxygen Radical Absorbance Capacity (ORAC) assay only caffeic acid and isoeugenol have stronger antioxidant abilities than the sinapinic acid [12]. Free radicals are very reactive chemical species with an unpaired electron. Because of their reactivity lipids, proteins, and DNA can be damaged by the radicals action. In consequence, they are responsible for many diseases such as cancer [13-16], cardiovascular disorders [17-21], atherosclerosis [22-24], and asthma, arthritis, neurodegenerative disorders: Alzheimer's [25-29], Parkinson's diseases, and dementia [30]. In the present study, the new curcumin derivative (1E,4Z,6E)-5-chloro-1,7-bis(4-hydroxy-3methoxyphenyl)hepta-1,4,6-trien-3-one (5-chlorocurcumin) was synthesised, and a structure was proposed based on spectroscopic evidence (Figure 1) and in view of the considerable importance of the curcumin as antioxidant the present work is also aimed for testing of 5-chlorocurcumin for free radical scavenging activity by using DPPH free radical scavenging methods.

\section{Experimental Section}

2.1. Chemistry. All chemicals used were of reagent grade (supplied by Malaysia | Sigma-Aldrich) and were used as received without further purification. The Fourier transform infrared (FTIR) spectra were measured using a Thermo Scientific Model Nicolet 6700 spectrophotometer. NMR spectra were recorded on a Model AVANCE III $600 \mathrm{MHz}$ spectrometer.

2.1.1. Synthesis of 5-Chlorocurcumin. Curcumin (1.23 g, $0.00334 \mathrm{Mol})$ was mixed with $\mathrm{POCl}_{3}(10 \mathrm{~mL})$, and the resulting suspension was refluxed for approximately 3 hours. The reaction was then cooled to room temperature and slowly poured onto crushed ice mixed with water. The violet solid formed was collected by filtration, washed with ice water, and recrystallised from acetonitrile.
2.1.2. Theoretical Studies. The molecular representation of the reference compound was plotted using ChemBioOffice 2010 software. All the quantum chemical calculations were performed using the Austin Model 1 (AM1), Parameterized Model number 3 (PM3), and Modified Neglect of Differential Overlap (MNDO) methodology, while the molecular atomic charges were calculated via the Mulliken charges [31].

2.2. Evaluation of Antioxidant Activity. Stock solution $(1 \mathrm{mg} / \mathrm{mL})$ was diluted to final concentrations of 20$100 \mu \mathrm{g} / \mathrm{mL}$. Ethanolic DPPH solution $(1 \mathrm{~mL}, 0.3 \mathrm{mmol})$ was added to sample solutions in DMSO $(3 \mathrm{~mL})$ at different concentrations $(50-300 \mu \mathrm{g} / \mathrm{mL})$ [32]. The mixture was shaken vigorously and allowed to stand at room temperature for $30 \mathrm{~min}$. The absorbance was then measured at $517 \mathrm{~nm}$ in a UV-Vis spectrophotometer. The lower absorbance of the reaction mixture indicates higher free radical scavenging activity. Ethanol was used as the solvent and ascorbic acid as the standard. The DPPH radical scavenger was calculated using the following equation:

$$
\text { Scavenging effect }=\frac{A_{0}-A_{1}}{A_{0}} \times 100 \text {, }
$$

where $A_{0}$ is the absorbance of the control reaction and $A_{1}$ is the absorbance in the presence of the samples or standards $A_{0}-A_{1}$.

\section{Results and Discussion}

3.1. Chemistry. The synthesis of (1E,4Z,6E)-5-chloro-1,7bis(4-hydroxy-3-methoxyphenyl)hepta-1,4,6-trien-3-one (5chlorocurcumin) was conducted via the reaction of curcumin with phosphorus oxychloride. For the FTIR spectrum of 5chlorocurcumin, the broad peak at $3412.9 \mathrm{~cm}^{-1}$ was due to O$\mathrm{H}$ stretching vibration, while the sharp peak at 1727.8 was due to carbonyl stretching. Peaks at $2959.7 \mathrm{~cm}^{-1}$ and $2931.6 \mathrm{~cm}^{-1}$ were assigned to aromatic rings on 5-chlorocurcumin. Peaks at $1598.8 \mathrm{~cm}^{-1}$ and $1513.0 \mathrm{~cm}^{-1}$ were typical of $\mathrm{C}=\mathrm{C}$ stretch vibrations. ${ }^{1} \mathrm{H}$ NMR $\left(\mathrm{CDCl}_{3}\right): \delta(\mathrm{ppm}) 7.5(\mathrm{H}-\mathrm{C}=\mathrm{C}) ; 7.27(\mathrm{H}-$ aromatic); $4.2(-\mathrm{OH}) ; 0.9\left(-\mathrm{OCH}_{3}\right) .{ }^{13} \mathrm{C} \mathrm{NMR}\left(\mathrm{CDCl}_{3}\right): \delta$ (ppm) $167.7(\mathrm{C}=\mathrm{O}) ; 128-132$ (C-aromatic); $68.18(\mathrm{C}-\mathrm{Cl}) ; 38.8$ $\left(-\mathrm{OCH}_{3}\right)$.

\subsection{Computational Studies}

3.2.1. Mulliken Charges. An earlier study [33-37] had shown that atomic charges were affected by the substituents present on rings. With the aid of a reference model, a 5-chlorocurcumin structure with optimised geometries and $3 \mathrm{D}$ geometrical structures is shown in Figure 2. The data showed that the highest atomic charge (Table 1) by AM1, PM3, and MNDO was $\left[\mathrm{O}_{23}-0.2950\right],\left[\mathrm{O}_{23}-0.3273\right]$, and $\left[\mathrm{O}_{23}-0.2891\right]$, respectively, followed by $\left[\mathrm{C}_{8}-0.2405\right]$, $\left[\mathrm{C}_{8}-0.2367\right]$, and $\left[\mathrm{O}_{24}-0.2779\right]$. These data clearly showed that these atoms were most reactive toward substitution reactions. The determined bond and twist angles, stretch, bend, stretch-bend, torsion, and the 3D geometrical structure 
TABLE 1: Mulliken charges for 5-chlorocurcumin using AM1, PM3, and MNDO methods.

\begin{tabular}{|c|c|c|c|}
\hline Atoms & AM1/charges & PM3/charges & MNDO/charges \\
\hline $\mathrm{C}(1)$ & 0.0738 & 0.0838 & 0.1059 \\
\hline $\mathrm{C}(2)$ & 0.0537 & 0.0527 & 0.1091 \\
\hline$C(3)$ & -0.1560 & -0.1338 & -0.0771 \\
\hline $\mathrm{C}(4)$ & -0.0681 & -0.0772 & -0.0744 \\
\hline$C(5)$ & -0.0968 & -0.0714 & -0.0203 \\
\hline$C(6)$ & -0.1977 & -0.1786 & -0.1330 \\
\hline$C(7)$ & -0.0352 & 0.0016 & 0.0425 \\
\hline $\mathrm{C}(8)$ & -0.2405 & -0.2367 & -0.1555 \\
\hline$C(9)$ & 0.2857 & 0.3486 & 0.2915 \\
\hline $\mathrm{C}(10)$ & -0.2361 & -0.2355 & -0.1313 \\
\hline $\mathrm{C}(11)$ & 0.0239 & -0.0453 & 0.0916 \\
\hline $\mathrm{C}(12)$ & -0.1694 & -0.1570 & -0.0985 \\
\hline $\mathrm{C}(13)$ & -0.0631 & -0.0429 & 0.0287 \\
\hline $\mathrm{C}(14)$ & -0.0687 & -0.0720 & -0.0827 \\
\hline $\mathrm{C}(15)$ & -0.1365 & -0.1180 & -0.0437 \\
\hline $\mathrm{C}(16)$ & 0.0406 & 0.0394 & 0.0798 \\
\hline $\mathrm{C}(17)$ & 0.0803 & 0.0896 & 0.1196 \\
\hline $\mathrm{C}(18)$ & -0.2025 & -0.1787 & -0.1413 \\
\hline $\mathrm{C}(19)$ & -0.0895 & -0.0718 & -0.0027 \\
\hline $\mathrm{O}(20)$ & -0.2250 & -0.2039 & -0.2256 \\
\hline $\mathrm{O}(21)$ & -0.2243 & -0.2029 & -0.2266 \\
\hline $\mathrm{Cl}(22)$ & 0.0111 & 0.1126 & -0.1004 \\
\hline $\mathrm{O}(23)$ & -0.2950 & -0.3273 & -0.2891 \\
\hline $\mathrm{O}(24)$ & -0.1940 & -0.1723 & -0.2779 \\
\hline$C(25)$ & -0.0772 & 0.0473 & 0.2150 \\
\hline $\mathrm{O}(26)$ & -0.1870 & -0.1655 & -0.2723 \\
\hline $\mathrm{C}(27)$ & -0.0803 & 0.0457 & 0.2157 \\
\hline $\mathrm{H}(28)$ & 0.1463 & 0.1225 & 0.0673 \\
\hline $\mathrm{H}(29)$ & 0.1369 & 0.1087 & 0.0601 \\
\hline $\mathrm{H}(30)$ & 0.1378 & 0.1113 & 0.0643 \\
\hline $\mathrm{H}(31)$ & 0.1480 & 0.1160 & 0.0646 \\
\hline $\mathrm{H}(32)$ & 0.1330 & 0.1151 & 0.0603 \\
\hline $\mathrm{H}(33)$ & 0.1399 & 0.1176 & 0.0654 \\
\hline $\mathrm{H}(34)$ & 0.1355 & 0.1171 & 0.0582 \\
\hline $\mathrm{H}(35)$ & 0.1389 & 0.1119 & 0.0605 \\
\hline $\mathrm{H}(36)$ & 0.1450 & 0.1211 & 0.0684 \\
\hline $\mathrm{H}(37)$ & 0.1385 & 0.1120 & 0.0659 \\
\hline $\mathrm{H}(38)$ & 0.1362 & 0.1105 & 0.0594 \\
\hline $\mathrm{H}(39)$ & 0.2159 & 0.1946 & 0.1915 \\
\hline $\mathrm{H}(40)$ & 0.2167 & 0.1947 & 0.1940 \\
\hline $\mathrm{H}(41)$ & 0.1083 & 0.0532 & 0.0156 \\
\hline $\mathrm{H}(42)$ & 0.0750 & 0.0279 & -0.0136 \\
\hline $\mathrm{H}(43)$ & 0.0653 & 0.0247 & -0.0189 \\
\hline $\mathrm{H}(44)$ & 0.1100 & 0.0534 & 0.0195 \\
\hline $\mathrm{H}(45)$ & 0.0732 & 0.0285 & -0.0150 \\
\hline $\mathrm{H}(46)$ & 0.0732 & 0.0285 & -0.0146 \\
\hline
\end{tabular}

indicated that this molecule was a nonplanar molecule with the stereochemistry $\mathrm{C}(7)-\mathrm{C}(8)$ : $(\mathrm{E}) ; \mathrm{C}(10)-\mathrm{C}(11)$ : $(\mathrm{Z})$; and $\mathrm{C}(12)-\mathrm{C}(13)$ : (E).

3.2.2. AM1, PM3, and MNDO. AM1, PM3, and MNDO calculations were performed for 5 -chlorocurcumin. The optimised molecular structure of the most stable form is shown in
TABLE 2: Total energy and heat of formation of 5-chlorocurcumin.

\begin{tabular}{lcc}
\hline Method & $\begin{array}{c}\text { Total energy } \\
(\text { Kcal/Mol) }\end{array}$ & $\begin{array}{c}\text { Heat of formation } \\
(\text { Kcal/Mol) }\end{array}$ \\
\hline AM1 & -113534.8813 & -99.534 \\
PM3 & -105232.4967 & -104.2199 \\
MNDO & -113377.2376 & -110.2337 \\
\hline
\end{tabular}

Figure 1, and the calculated energies are presented in Table 2. Molecular orbital calculations provided a detailed description of the orbitals including the spatial characteristics, nodal patterns, and individual atom contributions. The contour plots of the frontier orbitals for the ground state of 5chlorocurcumin are shown in Figure 3 together with the highest occupied molecular orbital (HOMO) and the lowest unoccupied molecular orbital (LUMO). It was interesting that both orbitals were substantially distributed over the conjugation plane.

In addition, it can be observed in Figure 3 that the HOMO orbitals were located on the substituted molecule, while the LUMO orbitals resembled those obtained for the unsubstituted molecule. Therefore, the substitution influenced the electron donation ability while imposing only a small impact on the electron acceptance ability.

The orbital energy levels of the HOMO and LUMO of 5chlorocurcumin are listed in Table 3. An electronic system with a larger HOMO-LUMO gap should be less reactive than one having a smaller gap. In the present study, the HOMOLUMO gap values of 5-chlorocurcumin by AM1, PM3, and MNDO methods were $-5.109,-4.642$, and $-5.944 \mathrm{eV}$, respectively. The lower value in the HOMO and LUMO energy gap would explain the eventual charge-transfer interaction taking place within the molecules. The low HOMO values for 5-chlorocurcumin indicated that this molecule had low ionisation energies, suggesting that it could lose electrons easily. These results indicated that 5-chlorocurcumin was potentially a good antioxidant.

The UV-Vis absorption spectrum of 5-chlorocurcumin was recorded in ethanol. Absorption peaks were observed at 255,281 , and $419 \mathrm{~nm}$ for 5-chlorocurcumin. These peaks were assumed to be the $\mathrm{n} \rightarrow \mathrm{p}^{*}$ and $\mathrm{p} \rightarrow \mathrm{p}^{*}$ transitions. The $3 \mathrm{D}$ plots of the HOMO-2, HOMO-1, HOMO, LUMO, $\mathrm{LUMO}+1$, and $\mathrm{LUMO}+2$ and the corresponding energy levels for 5-chlorocurcumin are shown in Figure 3. The theoretical electronic transfers (ET) for 5-chlorocurcumin by the AM1, PM3, and MNDO methods were at 242.677, 267.092, and $208.587 \mathrm{~nm}$, corresponding to the UV-Vis spectral absorption peaks and the electronic transfers of HOMO plus LUMO.

Figure 3 shows the six main orbitals contributing to the vertical electronic transitions of 5-chlorocurcumin. These orbitals, HOMO-2, HOMO-1, HOMO, LUMO, LUMO +1 and LUMO+2, represent the three highest occupied orbitals and the three lowest unoccupied orbitals in 5-chlorocurcumin. Similar spatial distributions of orbitals between $\mathrm{HOMO} /$ HOMO-1/HOMO-2 and LUMO/LUMO+1/LUMO+2 pairs and the population analysis for 5-chlorocurcumin indicated that the electronic transitions and the electron clouds of the HOMO were delocalised on the carbonyl, chloride and also 
TABLE 3: HOMO and LUMO energies (eV) of 5-chlorocurcumin.

\begin{tabular}{lccccccccc}
\hline Method & HOMO & LUMO & $\Delta E$ & HOMO - 1 & LUMO + 1 & $\Delta E$ & HOMO -2 & LUMO + 2 & $\Delta E$ \\
\hline AM1 & -10.845 & -5.736 & -5.109 & -11.189 & -2.871 & -8.318 & -11.531 & -0.291 & -11.24 \\
PM3 & -10.461 & -11.082 & -4.642 & -11.477 & -5.819 & -7.815 & -3.267 & -0.252 & -11.225 \\
MNDO & -10.962 & -11.086 & -5.944 & -11.364 & -5.018 & -9.373 & -1.713 & -0.546 & -10.818 \\
\hline
\end{tabular}

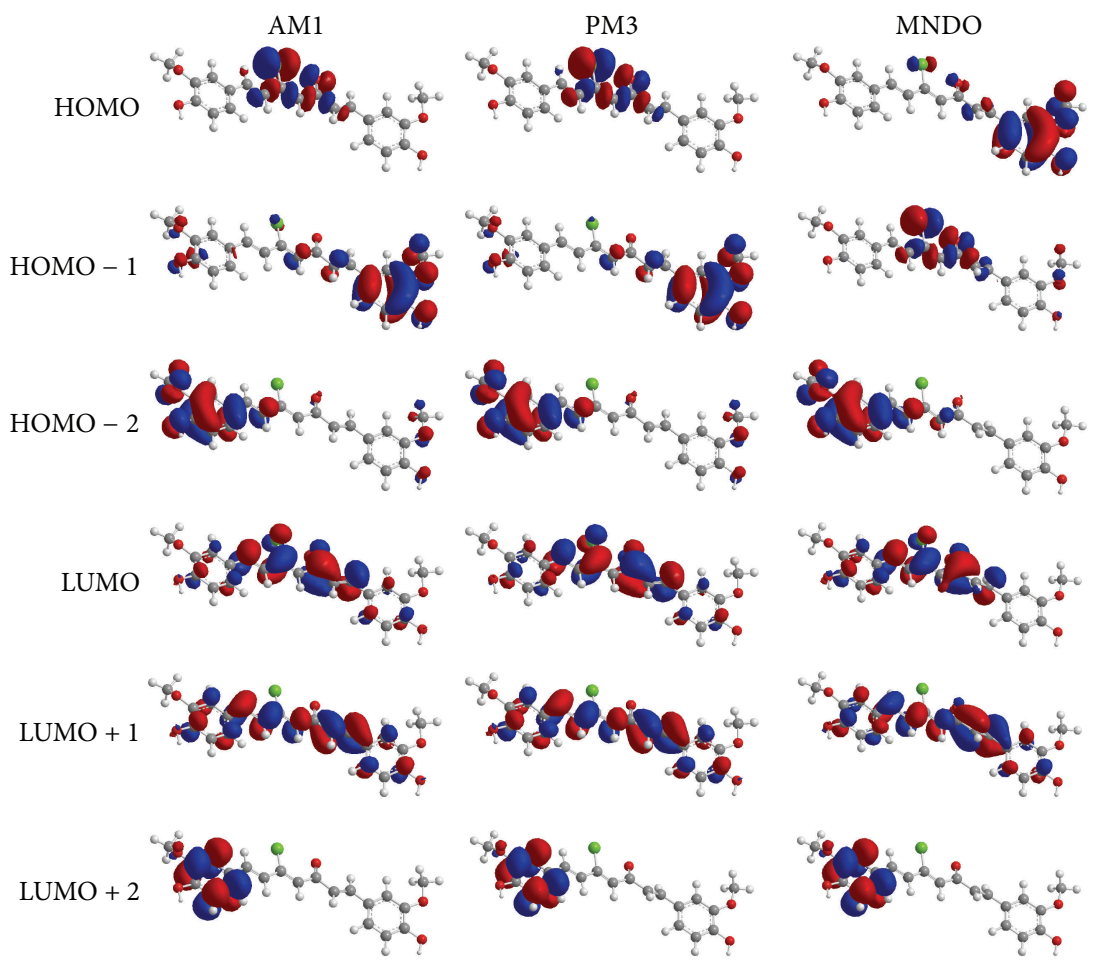

FIGURE 3: The highest occupied molecular orbital (HOMO) and the lowest unoccupied molecular orbital (LUMO) of 5-chlorocurcumin.

on carbon-carbon double bond (C10-C11) for AM1 and PM3 but delocalized on the benzene ring for MNDO. However, HOMO-1 was delocalised on the benzene ring for AM1 and PM3 but delocalised on the carbonyl, chloride and also on carbon-carbon double bond (C10-C11) for MNDO. Meanwhile, the HOMO-2 was delocalised on the benzene ring for all methods and also on carbon-carbon double bond (C10-C11) for AM1 and PM3. These orbitals were p-type bonding orbitals.

For comparison, the LUMO was found to be mainly delocalised on the carbonyl and chloride groups, while $\mathrm{LUMO}+1$ was delocalised on the carbonyl, chloride and benzene ring. The LUMO+2 was mainly delocalised on the benzene ring. These orbitals were p-type bonding orbitals. Finally, the LUMO was found to be mainly delocalised on the benzene ring. In all cases, the LUMOs exhibited $\mathrm{p}^{*}$-type antibonding orbital characteristics.

3.3. Radical Scavenging Activity. DPPH is a relatively stable nitrogen-centered free radical that easily accepts an electron or hydrogen radical to become a stable diamagnetic molecule. $\mathrm{DPPH}$ radicals react with suitable reducing agents as a result of which the electrons become paired off forming the corresponding hydrazine. The solution therefore loses colour stoichiometrically depending on the number of electrons taken up. Substances capable of donating electrons/hydrogen atoms are able to convert DPPH (purple) into their nonradical form 1, 1-diphenyl-2-picrylhydrazine (yellow), a reaction which can be followed spectrophotometrically. From results, it may be postulated that 5-chlorocurcumin was able to reduce the stable free radical DPPH to the yellow-coloured diphenylpicrylhydrazine exhibiting better free radical scavenging activity than the curcumin itself and standard antioxidant ascorbic acid. Structure activity relationship study showed that the antioxidant activity of 5-chlorocurcumin could be attributed to electron donating nature of the substituents like $-\mathrm{OH}$ and $-\mathrm{Cl}$ on 5-chlorocurcumin scaffold, reduce free radical DPPH, and prevent the damage of cell. The more the hydrogen donors are, the stronger the antioxidant activity is. These antioxidants should display antioxidant activity, if one or more groups like $-\mathrm{OH}$ and $-\mathrm{CH}_{3}$ are free, since they are known to be good hydrogen donors $[38,39]$. The DPPH radical assay provides an easy and rapid way to evaluate the antiradical activities of antioxidants. Determination of the reaction kinetic types DPPHH is a product of the reaction between $\mathrm{DPPH}^{\bullet}$ and an antioxidant:

$$
(\mathrm{AH}): \mathrm{DPPH}^{\bullet}+\mathrm{AH} \longrightarrow \mathrm{DPPHH}+\mathrm{A}^{\bullet}
$$




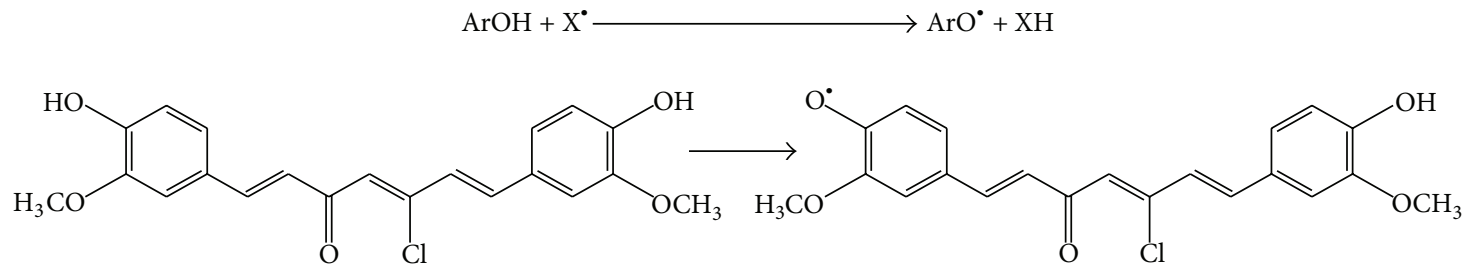

Scheme 1: Hydrogen atom transfer mechanism.<smiles>[Y][C@H](C)Oc1ccc(/C=C/C(=O)/C=C(Cl)/C=C/c2ccc(O)c(OC)c2)cc1OC</smiles>

Scheme 2: Single electron transfer mechanism.

The reversibility of the reaction is evaluated by adding $\mathrm{DPPHH}$ at the end of the reaction. If there is an increase in the percentage of remaining $\mathrm{DPPH}^{\bullet}$ at the plateau, the reaction is reversible; otherwise it is a complete reaction. DPPH was used as a stable free radical electron that accepts an electron or hydrogen radical to become a stable diamagnetic molecule [40]. DPPH is a stable free radical containing an odd electron in its structure and usually used for detection of the radical scavenging activity in chemical analysis [41]. The reduction capability of DPPH radicals was determined by decrease in its absorbance at $517 \mathrm{~nm}$ induced by antioxidants [42]. Graph was plotted with percentage scavenging effects on the $y$-axis and concentration $(\mu \mathrm{g} / \mathrm{mL})$ on the $x$-axis. The scavenging ability of the 5-chlorocurcumin was compared with ascorbic acid as a standard. 5-Chlorocurcumin showed good activities as a radical scavenger compared with curcumin and ascorbic acid (Figure 4).

There are postulated mechanisms for the reaction of 5chlorocurcumin as an antioxidant which depends on the hydrogen atoms (hydroxyl groups O20 and O21), where these atoms were under the influence of two effects, namely, resonance and inductive. The resonance effect of 5chlorocurcumin makes the release of hydrogen a free radical easy, while the inductive effect on benzene ring and methoxy group pushes the electrons toward oxygen free radical, resulting in the molecule becoming stable. The postulated mechanism depends on five known antioxidant mechanisms which describe antioxidant reactions [43-45].

First Mechanism Is Hydrogen Atom Transfer (HAT). Determining how antioxidants inherently donate their hydrogen atom to radicals, the environment in which they do this is also an important mechanistic consideration. For example, a solvent can affect the rate of hydrogen atom donation for a phenol by hydrogen bonding to the phenolic hydrogen, and in general, those solvents that have strong hydrogen bond accepting groups, that is, carbonyls or nitriles, tend to slow the rate of hydrogen atom donation substantially. This

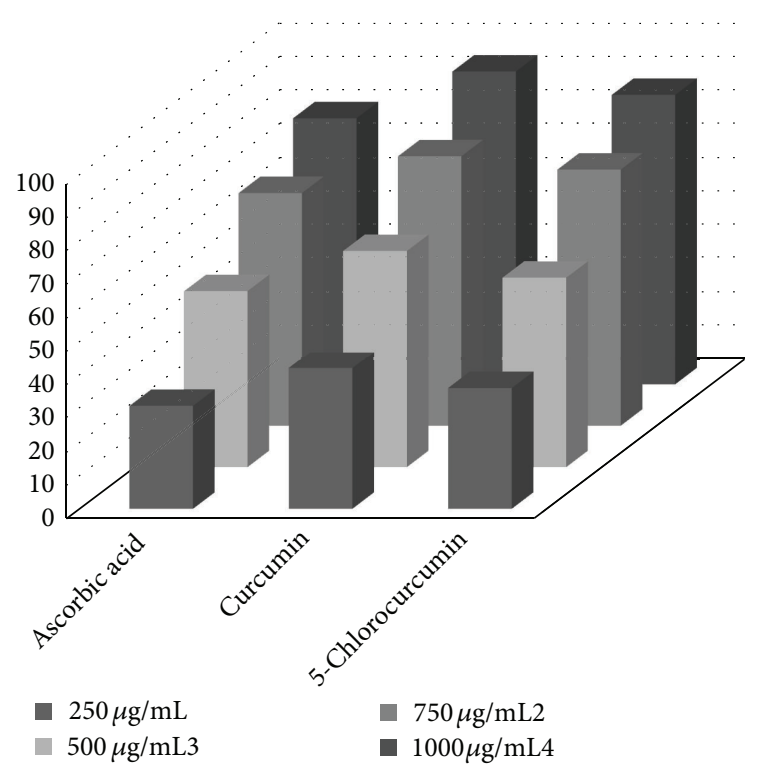

FIGURE 4: Scavenging effect of 5-chlorocurcumin, curcumin, and ascorbic acid at different concentrations $(15,30,45,60,80$, and $100 \mu \mathrm{g} / \mathrm{mL})$.

phenomenon supports a hydrogen atom-transfer mechanism since electron transfer would be facilitated under these conditions. Phenolic antioxidant reacts directly with a free radical which is neutralized, and a radical form of phenolic antioxidant appears. A numerical parameter associated with this mechanism is bond-dissociation enthalpy (BDE). The lower $\mathrm{BDE}$ parameter characterizes better antioxidant property. According to the Mulliken charges for 5-chlorocurcumin the hydroxyl group near the carbonyl $\left(\mathrm{O}_{20}\right)$ can release $H$ better than the one near chloro atom $\left(\mathrm{O}_{21}\right)$ (Scheme 1).

Second Mechanism Is Single Electron Transfer (SET). SET mechanism measures the ability of a potential antioxidant to transfer one electron to reduce compounds such as radicals, 
metals, and carbonyls by a reduction of a coloured oxidant as in the ABTS, DPPH, and FRAP assays [46]. SET assays measure the capacity of an antioxidant to reduce an oxidant which changes colour when reduced. The degree of colour change is correlated with the antioxidant activity. SET reactions are $\mathrm{pH}$-dependent and relatively slow and can require a long time to reach completion. Antioxidant capacity is based on the relative percent of the decrease in product rather than kinetics [47]. A numerical parameter related to the SET mechanism is adiabatic ionization potential (AIP), (Scheme 2).

\section{Conclusions}

In this study, 5-chlorocurcumin was synthesized by the reaction of curcumin with phosphorus oxychloride. 5Chlorocurcumin was characterized using various spectroscopic methods (FT-IR and NMR). The synthesised compound was studied theoretically, and the atomic charges and stereochemistry were estimated. The title compound was revealed to be nonplanar. The synthesized 5-chlorocurcumin was tested for antioxidant activity and found to be a superior antioxidant compound as compared to curcumin and ascorbic acid.

\section{Conflict of Interests}

The authors confirm that this paper content has no conflict of interests.

\section{Acknowledgments}

This study was supported by the University of Technology, Baghdad, Iraq, and Universiti Kebangsaan Malaysia under the DIP-2012-02 Grant.

\section{References}

[1] A. M. Anderson, M. S. Mitchell, and R. S. Mohan, "Design, synthesis, biological evaluation and molecular docking of curcumin analogues as antioxidant," Journal of Chemical Education, vol. 77, pp. 359-360, 2000.

[2] V. Lampe, "Synthesis von curcumin," Chemische Berichte, vol. 51, article 1347, 1918.

[3] S. Sreejayan and M. N. A. Rao, "Nitric oxide scavenging by curcuminoids," Journal of Pharmacy and Pharmacology, vol. 49, no. 1, pp. 105-107, 1997.

[4] M. N. Kunchandy and A. Rao, "Oxygen radical scavenging activity of curcumin," International Journal of Pharmaceutics, vol. 58, no. 3, pp. 237-240, 1990.

[5] S. V. Jovanovic, C. W. Boone, S. Steenken, M. Trinoga, and R. B. Kaskey, "How curcumin works preferentially with water soluble antioxidants," Journal of the American Chemical Society, vol. 123, no. 13, pp. 3064-3068, 2001.

[6] G. J. Kelloff, J. A. Crowell, E. T. Hawk et al., "Clinical development plan: 9-cis-retinoic acid," Journal of Cellular Biochemistry, vol. 26, pp. 158-167, 1996.

[7] N. Noguchi, E. Komuro, E. Niki, and R. Willson, "Action if curcumin as antioxidant against lipid peroxidation," Journal of Japan Oil Chemists' Society, vol. 43, pp. 1045-1051, 1994.
[8] R. Hong, W. H. Spohn, and M. Hung, "Curcumin inhibits tyrosine kinase activity of p185(neu) and also depletes p185(neul)," Clinical Cancer Research, vol. 5, no. 7, pp. 1884-1891, 1999.

[9] A. S. Jaiswal, B. P. Marlow, N. Gupta, and S. Narayan, “ $\beta$ catenin-mediated transactivation and cell—cell adhesion pathways are important in curcumin (diferuylmethane)-induced growth arrest and apoptosis in colon cancer cells," Oncogene, vol. 21, no. 55, pp. 8414-8427, 2002.

[10] F. T. Kolligs, M. T. Nieman, I. Winer et al., "ITF-2, a downstream target of the Wnt/TCF pathway, is activated in human cancers with $\beta$-catenin defects and promotes neoplastic transformation," Cancer Cell, vol. 1, no. 2, pp. 144-155, 2002.

[11] M. V. Kumaraswamy and S. Satish, "Antioxidant and antilipoxygenase activity of Thespesia lampas Dalz \& Gibs," Advances in Biological Research, vol. 2, no. 3-4, pp. 56-59, 2008.

[12] N. Nenadis, O. Lazaridou, and M.Z. Tsimidou, "Use of reference compounds in antioxidant activity assessment," Journal of Agricultural and Food Chemistry, vol. 55, no. 14, pp. 5452-5460, 2007.

[13] N. F. Boyd and V. McGuire, "The possible role of lipid peroxidation in breast cancer risk," Free Radical Biology and Medicine, vol. 10, no. 3-4, pp. 185-190, 1991.

[14] R. L. Nelson, "Dietary iron and colorectal cancer risk," Free Radical Biology and Medicine, vol. 12, no. 2, pp. 161-168, 1992.

[15] P. Knekt, A. Reunanen, H. Takkunen, A. Aromaa, M. Heliovaara, and T. Hakulinen, "Body iron stores and risk of cancer," International Journal of Cancer, vol. 56, no. 3, pp. 379-382, 1994.

[16] G. S. Omenn, G. E. Goodman, M. D. Thornquist et al., "Effects of a combination of beta carotene and vitamin A on lung cancer and cardiovascular disease," The New England Journal of Medicine, vol. 334, no. 18, pp. 1150-1155, 1996.

[17] R. A. Riemersma, D. A. Wood, C. C. A. Macintyre, R. A. Elton, K. F. Gey, and M. F. Oliver, "Risk of angina pectoris and plasma concentrations of vitamins $\mathrm{A}, \mathrm{C}$, and $\mathrm{E}$ and carotene," The Lancet, vol. 337, no. 8732, pp. 1-5, 1991.

[18] J. T. Salonen, K. Nyyssonen, H. Korpela, J. Tuomilehto, R. Seppanen, and R. Salonen, "High stored iron levels are associated with excess risk of myocardial infarction in Eastern Finnish men," Circulation, vol. 86, no. 3, pp. 803-811, 1992.

[19] D. A. Street, G. W. Comstock, R. M. Salkeld, W. Schüep, and M. J. Klag, "Serum antioxidants and myocardial infarction: are low levels of carotenoids and $\alpha$-tocopherol risk factors for myocardial infarction?" Circulation, vol. 90, no. 3, pp. 1154-1161, 1994.

[20] L. H. Kushi, A. R. Folsom, R. J. Prineas, P. J. Mink, Y. Wu, and R. M. Bostick, "Dietary antioxidant vitamins and death from coronary heart disease in postmenopausal women," The New England Journal of Medicine, vol. 334, no. 18, pp. 1156-1162, 1996.

[21] O. M. Panasenko, T. V. Vol'Nova, O. A. Azizova, and Y. A. Vladimirov, "Free radical modification of lipoproteins and cholesterol accumulation in cells upon atherosclerosis," Free Radical Biology and Medicine, vol. 10, no. 2, pp. 137-148, 1991.

[22] D. Steinberg, "Antioxidants and atherosclerosis. A current assessment," Circulation, vol. 84, no. 3, pp. 1420-1425, 1991.

[23] D. R. Janero, "Therapeutic potential of vitamin E in the pathogenesis of spontaneous atherosclerosis," Free Radical Biology and Medicine, vol. 11, no. 1, pp. 129-144, 1991.

[24] H. N. Hodis, W. J. Mack, L. LaBree et al., "Serial coronary angiographic evidence antioxidant vitamin intake reduces progression of coronary artery atherosclerosis," Journal of the American Medical Association, vol. 273, no. 23, pp. 1849-1854, 1995. 
[25] K. Hensley, D. A. Butterfield, M. Mattson et al., "A model for $\beta$ amyloid aggregation and neurotoxicity based on the free radical generating capacity of the peptide: implications of "molecular shrapnel" for Alzheimer's disease," Proceedings of the Western Pharmacology Society, vol. 38, pp. 113-120, 1995.

[26] K. Hensley, J. M. Carney, M. P. Mattson et al., "A model for $\beta$-amyloid aggregation and neurotoxicity based on free radical generation by the peptide: relevance to Alzheimer disease," Proceedings of the National Academy of Sciences of the United States of America, vol. 91, no. 8, pp. 3270-3274, 1994.

[27] D. A. Butterfield, L. Martin, J. M. Carney, and K. Hensley, "A $\beta(25-35)$ peptide displays $\mathrm{H}_{2} \mathrm{O}_{2}$-like reactivity towards aqueous $\mathrm{FE}^{2+}$, nitroxide spin probes, ant synaptosomal membrane proteins," Life Sciences, vol. 58, no. 3, pp. 217-228, 1995.

[28] D. A. Butterfield, " $\beta$-amyloid-associated free radical oxidative stress and neurotoxicity: implications for Alzheimer's disease," Chemical Research in Toxicology, vol. 10, no. 5, pp. 495-506, 1997.

[29] R. Sultana and D. A. Butterfield, "Redox proteomics studies of in vivo amyloid beta-peptide animal models of Alzheimer's disease: insight into the role of oxidative stress," Proteomics, vol. 2, no. 5, pp. 685-696, 2008.

[30] C. Rice-Evans, C. Rice-Evans, B. Halliwell, and G. G. Lunt, Free Radicals and Oxidative Stress: Environment, Drugs and Food Additives, Portland Press, London, UK, 1995.

[31] A. A. Al-Amiery, A. A. H. Kadhum, and A. B. Mohamad, "Antifungal and antioxidant activities of pyrrolidone thiosemicarbazone complexes," Bioinorganic Chemistry and Applications, vol. 2012, Article ID 795812, 5 pages, 2012.

[32] A. A. Al-Amiery, "Antimicrobial and antioxidant activities of new metal complexes derived from (E)-3-((5-phenyl1,3,4-oxadiazol-2-ylimino)methyl)naphthalen-2-ol," Medicinal Chemistry Research, vol. 21, pp. 3204-3213, 2012.

[33] Y. Chen, M. Wang, R. T. Rosen, and C. Ho, "2,2-diphenyl1-picrylhydrazyl radical-scavenging active components from Polygonum multiflorum Thunb," Journal of Agricultural and Food Chemistry, vol. 47, no. 6, pp. 2226-2228, 1999.

[34] A. A. Al-Amiery, Y. K. Al-Majedy, H. Abdulreazak, and H. Abood, "Synthesis, characterization, theoretical crystal structure, and antibacterial activities of some transition metal complexes of the thiosemicarbazone (Z)-2-(pyrrolidin-2ylidene)hydrazinecarbothioamide," Bioinorganic Chemistry and Applications, vol. 2011, Article ID 483101, 6 pages, 2011.

[35] A. A. H. Kadhum, A. B. Mohamad, A. A. Al-Amiery, and M. S. Takriff, "Antimicrobial and antioxidant activities of new metal complexes derived from 3-aminocoumarin," Molecules, vol. 16, no. 8, pp. 6969-6984, 2011.

[36] A. A. Al-Amiery, A. Y. Musa, A. A. H. Kadhum, and A. B. Mohamad, "The use of umbelliferone in the synthesis of new heterocyclic compounds," Molecules, vol. 16, no. 8, pp. 68336843, 2011.

[37] A. A. H. Kadhum, A. A. Al-Amiery, M. Shikara, and A. Mohamad, "Synthesis, structure elucidation and DFT studies of new thiadiazoles," International Journal of Physical Sciences, vol. 6, no. 29, pp. 6692-6697, 2012.

[38] F. A. Hashem, "Investigation of free radical scavenging activity by ESR for coumarins isolated from Tecoma radicans," Journal of Medical Sciences, vol. 7, no. 6, pp. 1027-1032, 2007.

[39] G. Cao, E. Sofic, and R. L. Prior, "Antioxidant capacity of tea and common vegetables," Journal of Agricultural and Food Chemistry, vol. 44, no. 11, pp. 3426-3431, 1996.

[40] A. A. Al-Amiery, Y. K. Al-Majedy, H. H. Ibrahim, and A. A. Al-Tamimi, "Antioxidant, antimicrobial, and theoretical studies of the thiosemicarbazone derivative Schiff base 2(2-imino-1- methylimidazolidin-4-ylidene) hydrazinecarbothioamide (IMHC)," Organic and Medicinal Chemistry Letters, vol. 2, article 4, 2012.

[41] J. R. Soares, T. C. P. Dinis, A. P. Cunha, and L. M. Almeida, "Antioxidant activities of some extracts of Thymus zygis," Free Radical Research, vol. 26, no. 5, pp. 469-478, 1997.

[42] P. Duh, Y. Tu, and G. Yen, "Antioxidant activity of water extract of Harng Jyur (Chyrsanthemum morifolium Ramat)," Lebensmittel-Wissenschaft \& Technologie, vol. 32, no. 5, pp. 269277, 1999.

[43] M. Leopoldini, N. Russo, and M. Toscano, "The molecular basis of working mechanism of natural polyphenolic antioxidants," Food Chemistry, vol. 125, no. 2, pp. 288-306, 2011.

[44] D. Mikulski, M. Szeląg, M. Molski, and R. Górniak, "Quantumchemical study on the antioxidation mechanisms of transresveratrol reactions with free radicals in the gas phase, water and ethanol environment," Journal of Molecular Structure, vol. 951, no. 1-3, pp. 37-48, 2010.

[45] Y. Shang, Y. Qian, X. Liu et al., "Radical-scavenging activity and mechanism of resveratrol-oriented analogues: influence of the solvent, radical, and substitution," Journal of Organic Chemistry, vol. 74, no. 14, pp. 5025-5031, 2009.

[46] D. Huang, O. U. Boxin, and R. L. Prior, "The chemistry behind antioxidant capacity assays," Journal of Agricultural and Food Chemistry, vol. 53, no. 6, pp. 1841-1856, 2005.

[47] M. Ozgen, R. N. Reese, A. Z. Tulio, J. C. Scheerens, and A. R. Miller, "Modified 2,2-azino-bis-3-ethylbenzothiazoline-6sulfonic acid (ABTS) method to measure antioxidant capacity of selected small fruits and comparison to ferric reducing antioxidant power (FRAP) and 2,2'-diphenyl-1-picrylhydrazyl (DPPH) methods," Journal of Agricultural and Food Chemistry, vol. 54, no. 4, pp. 1151-1157, 2006. 

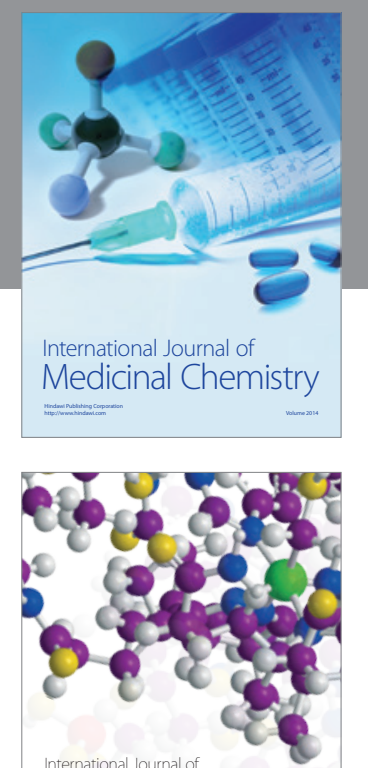

\section{Carbohydrate} Chemistry

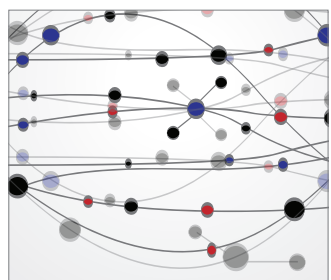

The Scientific World Journal
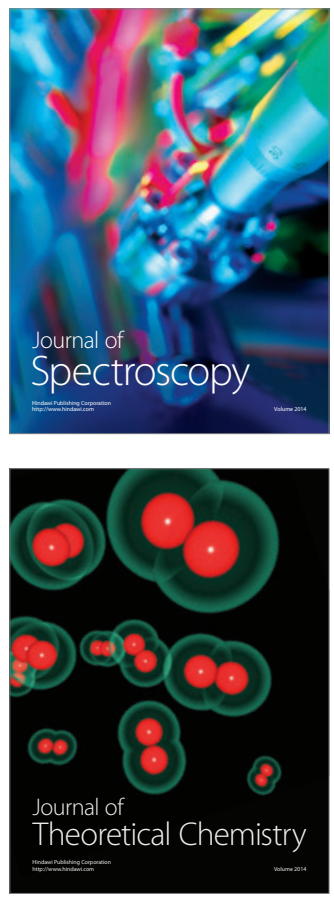
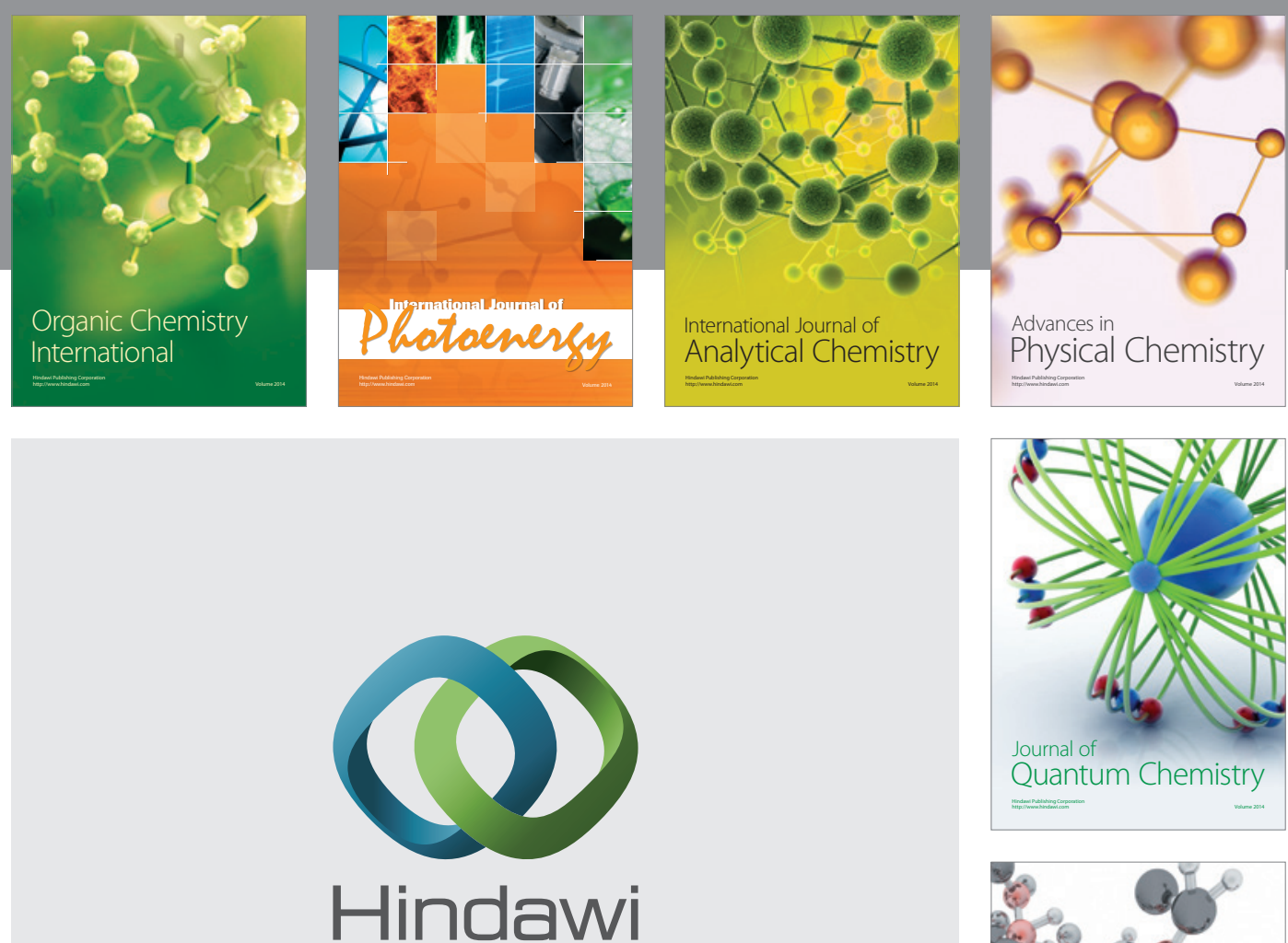

Submit your manuscripts at

http://www.hindawi.com

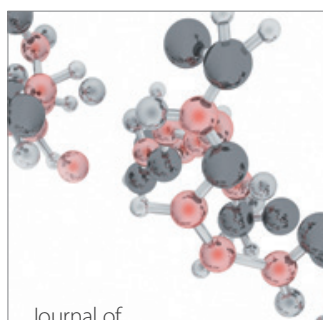

Analytical Methods

in Chemistry

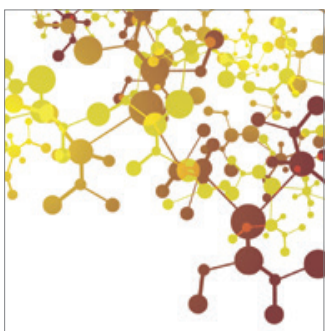

Journal of

Applied Chemistry

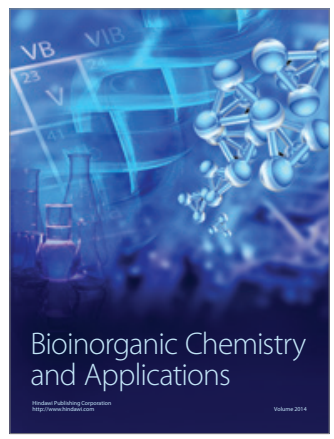

Inorganic Chemistry
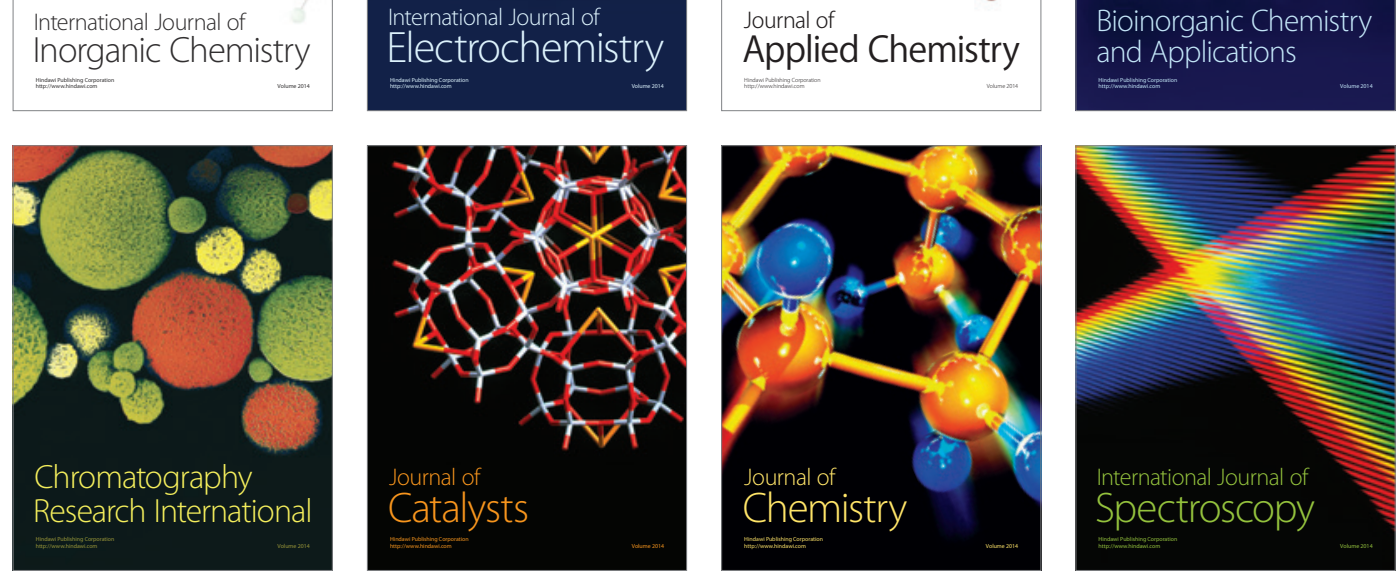